\title{
DOS JURISTAS EN EL EXILIO LATINOAMERICANO. LA TRAVESÍA DE MARIANO RUIZ-FUNES EN MÉXICO Y LUIS JIMÉNEZ DE ASÚA EN ARGENTINA
}

\author{
BEATRIZ GRACIA ARCE (UMU) \\ Universidad de Murcia \\ bga02601@um.es
}

\section{Resumen:}

El fin de la Guerra Civil precipitó la marcha al exilio de miles españoles. Diversos fueron los caminos que iniciaron al cruzar la frontera. En este trabajo analizaremos el caso particular de Mariano Ruiz-Funes y su peregrinar por el exilio que, finalmente, lo llevó a México, donde desarrolló su faceta de profesor de derecho penal en la Universidad Nacional Autónoma de México (UNAM) y el Colegio de México. Además de participar activamente en los espacios de sociabilidad del exilio en México, como la Unión de Profesores Universitarios Exiliados. Desde estos espacios trabajó activamente en la denuncia del nuevo Estado franquista. En ese periplo mantuvo su amistad con Luis Jiménez de Asúa, reconocido penalista que vivió el exilio en Argentina, donde trabajó incansablemente en su obra jurídica.

Palabras clave:

Exilio republicano - México - Argentina - Mariano Ruiz-Funes - Luis Jiménez de Asúa

\begin{abstract}
:
The end of the Civil war precipitated the march into the exile of thousands of Spaniards. In this paper we discuss the particular case of Mariano Ruiz-Funes and his pilgrimage through the exile that took him to Mexico. He was a professor of criminal law in the National Autonomous University of Mexico (UNAM) and in the Colegio de Mexico. He participated in the spaces of sociability of exile in Mexico, such as the Union of University Professors Exiles. From these spaces he worked actively in denouncing the new Francoist state. During this period he maintained his friendship with Luis Jiménez de Asúa, who lived his in exile in Argentina.
\end{abstract}

\section{Keywords:}

Republican Exile - Mexico - Argentina - Mariano Ruiz-Funes - Luis Jiménez de Asúa 


\title{
DOS JURISTAS EN EL EXILIO LATINOAMERICANO. LA TRAVESÍA DE MARIANO RUIZ-FUNES EN MÉXICO Y LUIS JIMÉNEZ DE ASÚA EN ARGENTINA
}

\author{
BEATRIZ GRACIA ARCE (UMU)
}

bga02601@um.es

\section{Travesías}

Cuando hablamos del exilio español de 1939, podemos hablar de "exilios". El desarrollo del conflicto bélico, la situación, cargo, condición social de esa enorme masa de gente que tuvo que marchar al finalizar la guerra, nos habla de circunstancias y situaciones bien diversas. De travesías tan distintas como las decisiones tomadas o no y en qué contexto se dieron. En circunstancias tan dramáticas como es una contienda civil y un exilio forzoso, muchas variables, que con frecuencia no responden a la razón lógica, nos permiten ver como los surcos del azar marcaron las vidas de los refugiados españoles de 1939.

El inicio del largo viaje del exilio de Mariano Ruiz-Funes se inició en Bélgica, desde que en agosto de 1937 fue destinado allí como embajador del gobierno de la República. El frente de lucha que supuso la diplomacia republicana, donde el mantenimiento de una embajada era prolongar la vida del legítimo gobierno republicano, hizo que Ruiz-Funes se encontrara al final de la guerra en el país belga hasta la entrega de la misma a las autoridades franquistas ${ }^{1}$. Tras ello, Mariano RuizFunes, junto con su familia, se trasladó a La Panne, municipio situado en la costa norte de Bélgica.

En la travesía del exilio, que iniciaba en ese instante Mariano Ruiz-Funes, le condicionó la realidad europea del momento. Él, con una afinidad mayor por Europa, se resistió mientras pudo a cruzar el Atlántico, como así prueba la carta de invitación del Instituto des Hautes Études de Belgique $^{2}$, en la cual le ofrecen impartir una serie de cursos para el curso académico 1939-1940, pero ante las circunstancias europeas, donde la guerra con Alemania era cada vez más una realidad no veía probable la opción de trabajar para la institución académica belga.

Descartada la opción europea, Mariano Ruiz-Funes barajó la posibilidad de marchar a Argentina, país donde había llegado el 8 agosto de 1939 Luis Jiménez de Asúa. Meses después Ruiz-Funes escribió a Asúa comentando la situación de incertidumbre en la que vivía ${ }^{3}$, después de que el Ministerio de Instrucción pública argentino le comunicara la falta de vacantes.

El camino de Jiménez de Asúa siguió en muchas ocasiones paralelo al de Mariano Ruiz-Funes, sobre todo desde finales de la Dictadura de Primo de Rivera, pues ambos fueron miembros de la comisión redactora de la Constitución republicana de 1931. Y con un destacado papel como jurista en la legislación republicana, Jiménez de Asúa fue destinado, desde octubre de 1936 a 7 de diciembre de 1938, como encargado de negocios de la República a Praga. Los objetivos de Asúa

\footnotetext{
${ }_{1}$ Su labor en la embajada queda desarrollada en: Gracia Arce, Beatriz, Trayectoria política e intelectual de Mariano RuizFunes: República y exilio. Murcia, Edit.um., 2014, págs. 150-160.

2 Archivo Universitario de la Universidad de Murcia- Fondo Mariano Ruiz-Funes (en adelante AUUM-FMRF). Caja 62. Carta del Instituto des Hautes Études de Belgique. Bruselas, 28 de octubre de 1939.

3 AUUM-FMRF. Caja 62. Carta de Mariano Ruiz-Funes a Jiménez de Asúa. Bruselas, 24 de mayo de 1939.
} 
es este país centroeuropeo consistieron en contrarrestar la política del Comité de No Intervención, además de intentar conseguir aprovisionamiento de armas, recursos materiales y humanos para la República en guerra ${ }^{4}$, y para este fin se entrevistó, entre otros, con el diplomático mexicano, Isidro Fabela, en noviembre de $1937^{5}$.

Tras acabar la guerra pasó unos meses en París, donde le ofrecieron una cátedra en la Universidad de la Sorbona ${ }^{6}$. Pero al igual que sucediera con otros profesionales cualificados, Asúa fue invitado por Alfonso Reyes, presidente de La Casa de España en México, quien le ofreció un contrato de un año prorrogable en la Universidad de México D. F.; contrato que no aceptó, optando por la oferta de Raúl Carranza, una elección que lo llevó a Buenos Aires ${ }^{7}$, donde después de ser convocado para dictar una serie de conferencias en La Plata, disertó sobre "La Ley Penal y su interpretación" el 25 de agosto de 1939 y, poco después, el Consejo Académico de la Facultad resolvió designarlo "profesor especial" a cargo de los Seminarios de Derecho Penal". Sus primeros años en Argentina no fueron fáciles, pues con el golpe militar de junio de 1943 Jiménez de Asúa decidió renunciar a su cargo de profesor en La Plata, en solidaridad con Peco y otros colegas que abandonan la docencia, y tuvo que viajar entonces, en 1944, a Quito, donde dio clases, y también a Guayaquil ${ }^{9}$.

Mariano Ruiz-Funes, ante la imposibilidad de marchar a Argentina, donde ya residía Jiménez de Asúa, consiguió partir de Bélgica en un carguero de carbón, donde él y su familia viajaron con una pareja de judíos, según nos relataron sus hijas en su testimonio oral, llegando a Nueva York donde los recibió Francisco García Lorca ${ }^{10}$, y desde allí siguieron a Cuba, pues habían pedido a Ruiz-Funes que impartiera una serie de conferencias. Fue ya en la isla desde donde contactó con Alfonso Reyes por medio de una carta en la que le hacía constar el deseo de colaborar con La Casa de España. Ruiz-Funes escribió desde México a Reyes ${ }^{11}$ :

"Mi respetable y querido amigo:

Le ratifico por medio de esta carta mi deseo, que ya le he expresado verbalmente, de colaborar con ustedes en las tareas de la Casa de España. Le acompaño mi currículo vital.

\footnotetext{
${ }^{4}$ Eiroa, Matilde, "La embajada en Praga y el servicio de información de Jiménez de Asúa", en Viñas, Ángel, Al servicio de la República. Diplomáticos y guerra civil, Madrid, Marcial Pons, 2010, págs. 207-208.

${ }^{5}$ Carta núm. 4, de Isidro Fabela. Ginebra, 11 de noviembre de 1937. En Fabela, I. y Rodríguez, Luis I. Diplomáticos de Cárdenas. Una trinchera mexicana en la Guerra Civil (1936-1940), Madrid, Trama editorial, 2007, págs. 42-47.

${ }^{6}$ Eiroa, Matilde, "La embajada en Praga...", op. cit., pág. 211.

7 Arrondo, César, Luis Jiménez de Asúa: Un docente que llegó del exilio a la Universidad Nacional de La Plata al servicio del Derecho, la Democracia y la Libertad, UCR, 2008 [en línea]. Disponible en http://www.unidadcivicaporlarepublica.es/nuestra $\% 20$ memoria $\% 202008 /$ imenez $\% 20 \mathrm{de} \% 20$ asua.htm\# edn3 (última consulta 30/04/17).

8 Figallo, Beatriz, "De Jiménez de Asúa a Perón: sus exilios como componentes de la política exterior hispanoargentina" [en línea], Temas de historia argentina y americana, 15, 2009, pág. 93. Disponible en http://bibliotecadigital.uca.edu.ar/repositorio/revistas/jimenez-asua-peron-exilios-componentes.pdf, (última consulta 30/04/17)

${ }^{9}$ Figallo, Beatriz, “De Jiménez de Asúa a Perón...”, op. cit., pág. 94.

${ }^{10}$ El testimonio del viaje a Nueva York y después a Cuba lo recojo en: Gracia Arce, Beatriz, Trayectoria política e intelectual de Mariano Ruiz-Funes: República y exilio, Murcia, Edit.um., 2014, págs. 191; y en Gracia Arce, Beatriz, "Mi infancia son recuerdos...: el testimonio intermedio y el exilio como trayecto", en Soto Carrasco, David, Nicolás García, José Neftalí y García Costa, Francisco Manuel. Memorias iberoamericanas: Historia, política y derecho, Pamplona, Aranzadi, 2015, pág. 85-99.

11 Archivo Histórico de El Colegio de México (en adelante, AHCM), La Casa de España, Caja 21, Expediente 13. Carta de Mariano Ruiz-Funes a Alfonso Reyes, México D.F, 17 de octubre de 1940. Esta carta ha sido publicada en la obra de Soler Vinyes, M., La Casa del éxodo. Los exiliados y su obra en La Casa de España y el Colegio de México (19381947), México, El Colegio de México, 1999, págs. 50-53.
} 
De acuerdo con mi preparación y con mi vocación científica constante, podría encargarme de explicar cursos monográficos o de carácter general, de derecho penal, de criminología, de penología".

A la carta adjuntó el jurista su currículum vitae ${ }^{12}$, con una lista de sus publicaciones más relevantes; y Alfonso Reyes, en un corto espacio de tiempo, le manifestó lo siguiente:

"Tendré el mayor gusto en proponer sus planes a la consideración de nuestra Junta de gobierno. Quisiera cambiar unas palabras con usted, pues entiendo que tiene usted también algún otro proyecto sobre cierto seminario de Derecho Penal que acaso pudiera determinar su vinculación permanente con nuestros trabajos"13.

Jiménez de Asúa en Argentina y Mariano Ruiz-Funes en México anduvieron el camino del exilio desde la posición de juristas ampliamente cualificados y de reconocido prestigio. Un camino del destierro donde lo político y lo intelectual, a veces, era una débil frontera. Así, Mariano RuizFunes estuvo presente en los tortuosos momentos de consolidación del gobierno republicano en el exilio; mientras que Jiménez de Asúa era nombrado presidente de las Cortes Republicanas en 1945.

\section{Juristas en el exilio}

"El exilio es un desgarrón que no acaba de desgarrarse, una herida que no cicatriza, una puerta que parece abrirse y nunca se abre. El exiliado descubre con estupor, primero con dolor, después con cierta ironía más tarde, en el momento mismo en que objetivamente ha terminado su exilio, que el tiempo no ha pasado impunemente, y que tanto si vuelve como si no vuelve, jamás dejará de ser un exiliado" ${ }^{\text {"14. }}$.

La correspondencia entre Ruiz-Funes y Jiménez de Asúa ${ }^{15}$ fue habitual durante el periodo en el que coincidieron en el exilio ${ }^{16}$, y de la misma podemos extraer la impresión de que tenían una relación de sinceridad clara y amistad en todo momento. Da muestra de los lazos de unión y apoyo entre el colectivo de intelectuales exiliados.

La estrecha relación del colectivo intelectual, como fue el ejemplo vivido por Mariano RuizFunes y Luis Jiménez de Asúa, se remontaba al periodo de la dictadura primorriverista; en muchos casos con culturas políticas afines y con bases intelectuales similares (como el peso de la cultura institucionista ${ }^{17}$ ), lo que explica la capacidad que demostró el exilio cultural por coaligarse y crear espacios de sociabilidad que actuaran como verdaderos espacios de resistencia en el exterior al reconocimiento de la dictadura franquista y al mantenimiento del espíritu de legitimidad de la causa republicana.

Mariano Ruiz-Funes, emplazado en México, país que constituyó una plataforma vital para las instituciones políticas y culturales del exilio, participó de forma muy activa en las diferentes organizaciones que agruparon a profesores, escritores, etcétera. Destacado es el caso de la Unión de Profesores en el Exilio, que nació en París en 1939, aunque con posterioridad tuvo su sede

\footnotetext{
12AHCM: Currículum vitae de Mariano Ruiz-Funes enviado a Alfonso Reyes.

13 AHCM. La Casa de España, Caja 21, Expediente 13. Carta de Alfonso Reyes a Mariano Ruiz-Funes, México D.F, 19 de octubre de 1940. También publicada por Soler Vinyes, M., La Casa del éxodo, op. cit., pág. 53.

14 Sánchez Vázquez, Adolfo, jExilio!, México, Tinta libre, 1977, págs. 200-203.

${ }^{15} \mathrm{La}$ correspondencia con la que hemos trabajado para este estudio se encuentra en el Archivo Universitario de la Universidad de Murcia en el Fondo Mariano Ruiz-Funes (AUUM- FMR), así como en el Fondo Luis Jiménez de Asúa de la Fundación Pablo Iglesias (FPI).

${ }^{16}$ Hay que puntualizar la temprana muerte de Mariano Ruiz-Funes en 1953.

${ }_{17}$ De Hoyos Puente, Jorge,; Viva la inteligencia! El legado de la cultura institucionista en el exilio republicano de 1939, Madrid, Biblioteca Nueva, 2016.
} 
presidencial en La Habana, donde residía Gustavo Pittaluga. La Unión de Profesores publicó un Boletín Informativo ${ }^{18}$ en cuyo primer número Mariano publicó una crítica a la nueva legislación universitaria bajo la dictadura franquista. Además en ese número ${ }^{19}$ fijaron que la organización Unión de Profesores tenía que servir de soporte para el desarrollo de instituciones culturales, la investigación científica y ser soporte para el estudio tanto a estudiantes como a profesores.

Desde agosto de 1943 Ruiz-Funes actuó como vicepresidente de la Unión de Profesores. En la primera reunión celebrada en La Habana intervino con una ponencia titulada "El régimen actual de España" 20 , donde calificó al régimen de Franco como "golpe de estado internacional", situándolo en la órbita del eje Berlín-Roma ${ }^{21}$, además de profundizar en las nulas garantías jurídicas que existían en España:

"Penas infames, confiscación de bienes, muerte civil, ejecuciones públicas con una nota impresionante de infamia; sustitución de unos métodos de ejecución por otros más crueles, castigos corporales (...), derogación de la cosa juzgada suprimiendo todas las garantías de justicia; extradición persiguiendo la policía española, con desconocimiento de la soberanía nacional a los hombres políticos que se refugiaban en otros países ${ }^{22 \%}$.

En la línea invisible que en el exilio separaba las manifestaciones culturales de las políticas, prácticamente todo tenía un trasfondo político, en tanto que eran voces de refugiados políticos las que reclamaban. También el Boletín Informativo se movió en el campo político, y fueron utilizadas sus páginas por Mariano Ruiz-Funes para pedir, aprovechando la visita a México del representante colombiano de la UNRRA, Eduardo Santos, que esta organización tomara partido por España republicana en el exilio ${ }^{23}$.

Ante el nuevo contexto europeo y trabajando siempre con la idea del regreso a España, los profesores universitarios elaboraron un proyecto de normas para el reintegro a sus cátedras de los profesores que habían sido destituidos por la represión franquista. El objetivo era devolver a sus cátedras "a todo profesor que se encontrara en sus cátedras el 18 de julio"; y en el caso de que estas cátedras hubieran sido suprimidas o asumidas por otra persona, se restablecerían en su origen; y en el caso de que no se quisiera retornar a España a ocupar la plaza, ésta quedaría en excedencia; y se procedería a la recuperación del número de escalafón ${ }^{24}$.

Paralelamente a esta faceta pública de los profesores universitarios en el exilio, lo cierto es que el camino individual de cada uno de ellos tuvo que ir forjándose poco a poco con un duro trabajo, que pasaba por la adaptación al país de acogida, superar las trabas burocráticas para ejercer la profesión y contar con un contrato estable de trabajo.

Como hemos apuntado al inicio de este artículo, Ruiz-Funes fue acogido en México por La Casa de España, si bien no contó con una estabilidad económica, porque en los primeros momentos lo contrataron para impartir seminarios y para que trazara un anteproyecto de Instituto de Estudios Penales, basado en el modelo de la Antigua Escuela de Criminología de Madrid ${ }^{25}$.

\footnotetext{
18 Cobos Bueno, J.M, Pulgarín Guerrero, A., Carapeto Sierra, C, "El Boletín Informativo de la Unión de Profesores Españoles Universitarios en el Extranjero”, LLULL, vol. 27, 2004, págs. 27-60.

19 AUUM-FMRF, Caja 51. Boletin Informativo de la Unión de Profesores Universitarios Españoles en el Extranjero (sección México), Año I, agosto 1943, nº1.

20 VV.AA. Libro de la primera reunión de Profesores Universitarios Españoles Emigrados, La Habana, 1944, págs. $207-211$.

${ }^{21}$ Esto queda analizado en: Gracia Arce, Beatriz, Trayectoria política e intelectual..., op. cit., págs. 231-233.

22 VV.AA. Libro de la primera reunión de Profesores Universitarios..., op. cit., pág. 210.

23 AUUM-FMRF, Caja 51. Boletín Informativo de la Unión de Profesores Universitarios Españoles en el Extranjero (sección México), año II, nº5. 15-16, octubre-noviembre 1944.

24 AUUM-FMRF, Caja 51. Proyecto de normas para el reintegro a sus cátedras de los universitarios destituidos (firmado por José Giral).

25 AUUM-FMRF, Caja 27,2. Anteproyecto de un Instituto de Estudios Penales. Archivo Histórico del Colegio de México (AHCM). La Casa de España, Caja 21, Expediente 13.
} 
Esta realidad de lo llevó a realizar trabajos para otras universidades del país azteca, para el Colegio de Estudios Superiores de Guanajuato, Universidad de Morelia y la Universidad de San Luis Potosí. Su vinculación con El Colegio de México le facilitó la entrada como profesor en la Universidad Nacional Autónoma de México (UNAM), cuando Vicente Peniche contactó con Ruiz-Funes en 1943, pero no fue hasta marzo de 1950 cuando fue designado profesor de la Cátedra de Criminología del doctorado en Derecho que se impartía en la Escuela Nacional de Jurisprudencia de la UNAM.

De la generación de juristas que se habían desarrollado en el periodo republicano, Jiménez de Asúa fue de los pocos que no estuvo afincado en México, pues como hemos apuntado, consiguió incorporarse a La Universidad de La Plata (Provincia de Buenos Aires) como profesor extraordinario en abril de 1940, donde sería nombrado director del Instituto de Altos Estudios Jurídicos y del Instituto de Criminología. Desde Argentina, la correspondencia que Asúa dirigía a Ruiz-Funes en México nos permite ver el conocimiento que ambos tenían de la obra jurídica del otro producida en el exilio, y cómo vivían su condición de exiliados ante la perspectiva de un imposible regreso a España. Así, a través de una de sus múltiples cartas, Luis Jiménez de Asúa instaba a Ruiz-Funes en 1947 a que buscara sólidos anclajes en México frente al infructuoso retorno que se dibujaba en el horizonte tras la finalización de la Segunda Guerra mundial y el definitivo abandono de la causa republicana por los antiguos aliados:

“(...) creo que debes pensar mucho en lo que ahora te digo. No se trata de que aceptes éstas o aquellas conferencias en Lima, en Río o en el Ecuador, sino de resolver definitivamente tu vida, ya que estarás como yo persuadido de que, salvo circunstancias que ahora no columbramos, jamás volveremos a nuestra patria.

Es preciso resolver la vida de un modo definitivo y decidirte a trasladarte con tu familia a un lugar donde tengas un sueldo fijo que te permita vivir" ${ }^{26}$.

En una carta anterior ya Jiménez de Asúa le había mostrado su pesimismo a Ruiz-Funes en cuanto al retorno a España, y por tanto la necesidad de que se planteara aceptar la Cátedra del Instituto de Criminología. Escribe Asúa:

"Creo que pensarás igual que yo con respecto a lo de España. Salvo incidentes incalculables hoy, no volveremos nunca. Por eso quizá te convenga ir pensando que para la fecha en que yo me traslade a Venezuela te convendría a ti tomar la cátedra de Criminología en ese Instituto, caso que yo lograse que te la pagaran bien. Lo que yo te insinuaría que era la conveniencia de trasladarte a vivir a Venezuela en vez de seguir en México, si todos los asuntos que proyecto se desarrollan en la forma en que los he planeado" 27 .

A lo largo del año 1948 esta posibilidad se fue diluyendo por la situación política en Venezuela. Y para inicios de 1949 Asúa comentaba a Ruiz-Funes que con los cambios en el gobierno venezolano todo se complicaba ${ }^{28}$, si bien los intentos de Jiménez de Asúa para abrir más vías de trabajo a Ruiz-Funes fueron constantes. La faceta de conferenciante de Ruiz-Funes lo llevó a impartir cursos prácticamente en toda Latinoamérica, ofreciendo Asúa a Ruiz-Funes la posibilidad también de impartir una serie de conferencias en Tucumán y en Córdoba a través de los Colegios de Abogados, si bien explica "que si no te servían de ingreso, por lo menos te darán para costear tu permanencia en esta grata tierra" 29 .

\footnotetext{
26 AUUM-FMRF, Caja 62, Carta de Jiménez de Asúa a Ruiz-Funes (Fundación Pablo Iglesias), Buenos Aires, 28 de junio de 1947.

27 AHFPI- ALJA, 421-43. Carta de Jiménez de Asúa a Ruiz-Funes, Buenos Aires, 19 de junio de 1947.

28 AHPI-ALJA, 421-43. Carta de Jiménez de Asúa a Ruiz-Funes, Buenos Aires, 12 de febrero de 1949.

29 AHFPI-ALJA, 421-43. Carta de Jiménez de Asúa a Ruiz-Funes, Buenos Aires, 23 de septiembre de 1947.
} 
Era frecuente en la correspondencia mantenida entre ambos exiliados que comentasen su percepción sobre la obra del otro, o la recepción de artículos. En este sentido Luis Jiménez de Asúa comentaba con Mariano Ruiz-Funes en alguna de sus cartas la necesidad de que en el ámbito jurídico se celebraran congresos de criminología, como a los que ellos habían podido asistir en Europa, 'con un número concreto de temas que interesaran a todos los países de este continente y se debatiesen en serio y por delegados oficiales ${ }^{30}$.

El periodo entre 1947 y 1950 fue verdaderamente fructífero para la producción científica de Mariano Ruiz-Funes, quien escribió en distintas revistas especializadas como Criminalia o La Ley, y recibió el premio Afranio Peixoto en Brasil, con su obra Criminología de guerra (1947). Las temáticas en las que se centró en esta etapa fueron fundamentalmente su valoración sobre los crímenes de las guerras, genocidio, venganza, las consecuencias criminológicas de la guerra, el delito político o la prisión. Aunque sobre estas temáticas también trabajó en distintas publicaciones periódicas, algunas de ellas destinadas al gran público (como Bohemia, Carteles, Ultra o las publicaciones periódicas del Ateneo Libertad de México ${ }^{31}$ ), era habitual, sin embargo, el comentario entre ambos penalistas de textos escritos en revistas científicas del área o de los libros que iban publicando: textos como La peligrosidad o La crisis de la prisión (1949), fueron considerados por Jiménez de Asúa como dos obras magníficas ${ }^{32}$. En la segunda, Mariano RuizFunes trabajó sobre en qué condiciones se van a dar las penas, siempre en la búsqueda del respeto de la dignidad humana. En la obra citada escribe:

"[La prisión] contiene pero no corrige. Cumple un fin que no es su fin. Constituye un obstáculo negativo, pero no llena ninguna función positiva. Mantiene al hombre apartado de la sociedad, pero no crea en él aquellas disposiciones sociales cuya carencia puso de relieve el delito" ${ }^{33}$.

En la misma sostiene la individualización de las penas, y señala que hay que fijar los grados y variedades de la organización penitenciaria que habría de determinarse y de establecerse pensando en cada delincuente ${ }^{34}$. Esta concepción bebe directamente del krausismo que sostenía que debía concebirse la prisión con el objetivo de reformar al delincuente. Es por ello fundamental sostiene Ruiz-Funes- velar por la educación de un hombre, que es preocuparse por todas las acciones y colocarlo en una posición en la que se pueda influir para reinsertarlo ${ }^{35}$.

Para el penalista murciano se convirtió en algo indispensable delimitar el tratamiento que se le daba al preso y cuál debería de ser el correcto. Consideraba que las directrices acordadas en el Congreso Internacional de La Haya (1950) eran medidas positivas para su aplicación, como "la separación de hombres y mujeres y de menores y adultos; aislamiento celular nocturno; respetar la diversidad de credos; dotar a la prisión de biblioteca, exclusión de la tortura, castigos corporales o restricciones alimentarias" 36 .

\footnotetext{
30 AHFPI- ALJA, 421-43. Carta de Jiménez de Asúa a Ruiz-Funes, Buenos Aires, 4 de diciembre de 1947.

${ }^{31}$ Esta temática la desarrollo con más profundidad en: Gracia Arce, Beatriz, "Los escritos de Mariano Ruiz-Funes desde el exilio: las consecuencias de la Segunda Guerra Mundial y la crítica al franquismo", Vinculos de Historia, núm.3 (2014), págs. 290-301; Gracia Arce, Beatriz, "Mariano Ruiz-Funes y su aportación al exilio jurídico en México", Cuadernos Iberoamericanos. Revista de Historia y Comunicación (CIHC), No1- año 2015, págs. 30-45; Gracia Arce, Beatriz, "La Segunda Guerra Mundial vista por Mariano Ruiz-Funes", en Serra Puche, Mari Carmen, Mejía Flores, José Francisco, Sola Ayape, Carlos (Coords.), Política y sociedad en el exilio republicano español. México, Centro de investigaciones sobre América Latina y el Caribe - Universidad Nacional Autónoma de México, 2015, págs. 131-142. 32 AHPI-ALJA, 421-43. Carta de Jiménez de Asúa a Ruiz-Funes, Buenos Aires, 17 de mayo de 1949.

33 Ruiz-Funes García, Mariano, La crisis de la prisión. La Habana, Montero editor, 1949, págs. 7-8.

34 Ruiz-Funes García, Mariano, La crisis de..., op. cit., pág. 45.

35 Ruiz-Funes García, Mariano, La crisis de..., op. cit., págs. 80-81.

36 AUUM-FMRF, Caja 31 bis, 074. "Tratamiento de los presos" (original mecanografiado) publicado en Novedades el 5 de septiembre de 1950. Sobre el tratamiento de presos y su conducta publicó Ruiz-Funes, M, "La conducta de los reclusos. Su control", Criminalia, Año XIX, N², febrero de 1953.
} 
En dicho Congreso de La Haya participó Luis Jiménez de Asúa, quien escribió a Mariano RuizFunes: "Intervine en el Congreso de La Haya con más gusto que en París. Sobre estado peligroso dije muy poco y mis intervenciones más importantes fueron sobre el concepto criminológico del delito" "37; temática que Jiménez de Asúa plasmó en lo que fue una de sus grandes obras, El criminalista, obra compuesta por siete tomos publicados en Argentina, que junto a su Tratado de Derecho Penal, componen dos obras fundamentales del penalista y que reúnen el trabajo de toda una vida.

Mariano Ruiz-Funes publicó en 1951, en la Revista de Derecho de México, una nota bibliográfica ${ }^{38}$ sobre el Tomo II del Tratado de Derecho Penal de Jiménez de Asúa, donde valoraba positivamente el carácter legalista de su visión sobre la analogía en derecho penal, así como el estudio sobre la extradición, asilo político dentro del derecho internacional y la necesidad de trabajar por la unificación del derecho penal, máxime en un contexto donde era necesaria la actualización del concepto de 'crímenes de guerra' atendiendo a la reciente finalización de la guerra y al procesamiento de los 'crímenes de guerra' japoneses y los juicios de Núremberg. Por su parte en el verano de 1951 Asúa comentaba con Ruiz-Funes un artículo que escribió titulado "Legítima defensa del Estado", del agrado de Ruiz-Funes, reflexión que nació en respuesta a las palabras del jurista Sánchez Tejerina quien, en la apertura de curso 1940-1941 en la Universidad de Salamanca, preparó un discurso que versaba sobre el "Alzamiento Nacional Español", entendido como un caso de legítima defensa. Era presumible que utilizó su intervención para justificar el alzamiento militar contra la República, subrayando que los crímenes cometidos por las fuerzas nacionales no podían ser imputados a sus autores sino a las víctimas, quienes habían provocado la situación previa ${ }^{39}$. Tejerina, que sostuvo la legalidad del golpe contra la República, fue premiado con la Cátedra de Derecho Penal de la Universidad Central de Madrid. Esto ejemplifica claramente la brecha que supuso la Guerra Civil y la instauración del Régimen franquista, que marcó las vidas de Ruiz-Funes y Asúa: el concepto de justicia de la dictadura consiguió retorcer los términos jurídicos para hacerlos suyos y utilizarlos en su beneficio. Como el propio Ruiz-Funes definió: "Los rebeldes juzgan a los civiles; es una situación subvertida, semejante a la que se produciría cuando el delincuente que comparece ante el juez le dijera: señor juez, vengo a juzgarlo a usted" ${ }^{\prime 4}$. El premio que otorgó la dictadura a sus juristas afines fue que éstos pasasen a ocupar el vacío dejado por los profesores que fueron fusilados, depurados o que se vieron obligados a marchar al exilio. Ruiz-Funes puso de relieve y criticó esta anómala situación en varias de sus intervenciones públicas, por ejemplo cuando hablaba de que la universidad se había convertido en la "universidad de un régimen falangista", donde:

“(...) la influencia intelectual ha sustituido la influencia política. Para ello se ha valido del profesorado. Dentro de él ha hecho tres reformas: a. destruir a los que nos marchamos; b. Someter a aquella parte de los que se quedaron que se ha puesto a sus órdenes; c. Reclutar otros nuevos" ${ }^{\prime 4}$.

Por su parte Jiménez de Asúa consiguió publicar su artículo "La legítima defensa del Estado" en México. En él subrayaba que el único partidario de ese concepto de la defensa del Estado era Tejerina, y que éste "lo expresa con infundables pretensiones de novedad, en párrafos zurdos y coloreados de una combatividad política no sólo inactual, sino impropia de quien en toda

\footnotetext{
${ }^{37}$ AHPI-ALJA, 421-43. Carta de Jiménez de Asúa a Ruiz-Funes, Buenos Aires, 2 de diciembre de 1950.

38 Ruiz-Funes, Mariano, "Luis Jiménez de Asúa. Tratado de Derecho Penal, Tomo II. Filosofía y Ley penal”, Revista de Derecho de México, No1-2, 1951, págs. 309-315.

39 Ferré Olivé, Juan Carlos, República y Guerra Civil. Lección inangural del curso académico 2009-2010, Universidad de Huelva, Huelva, 2009, pág. 27.

40 VV.AA., Libro de La primera reunión de Profesores Universitarios..., op. cit., pág. 208.

41 AUUM-FMRF, Caja 51. Boletín Informativo de la Unión de Profesores Universitarios Españoles en el Extranjero (sección México), año II, n5, 15-16, octubre-noviembre 1944.
} 
coyuntura quiere hacer inmerecida gala de generosidad cristiana ${ }^{42}$ \%. Especificaba en una nota al pie:

“(...) su mal hilvanado pensamiento y a su defectuosa sintaxis, con todo el artículo en que están contenidas. Pero lo peor es el odio con que habla de todos los españoles que no tienen su furibundo credo, odio parejo al de aquellos sacerdotes que en las guerras carlistas mataban a sus prójimos a balazos, escudando sus tendencias homicidas en la finalidad religiosa"43.

Lo cierto es que la trayectoria de Tejerina distó mucho de la Jiménez de Asúa y Ruiz-Funes, pues ya en época republicana había sido un firme defensor de la pena de muerte en el momento en el que se derogó en el Código Penal de 1932, apoyándose en el concepto de "legítima defensa" ". Mismo concepto que empleó para justificar la Guerra Civil como una "Guerra de liberación" "45. Fue también uno de los artífices de la Ley sobre represión de la Masonería y el Comunismo, encargándose de juzgar a la logia salmantina, y formó parte como juez ${ }^{46}$ del Tribunal Especial de Represión de la Masonería y el Comunismo ${ }^{47}$.

La situación española marcada en los últimos momentos de vida de Mariano Ruiz-Funes se caracterizó por el posicionamiento progresivo de la ONU a admitir al Régimen de Franco, lo que pesó sobre los ánimos tanto de Funes como de Asúa, y les llevó a mostrarse críticos con los propios gobiernos "hispanoamericanos que votan en la ONU a favor de Franco, porque así piensan sus pueblos" ${ }^{\prime \prime 8}$.

Sólo unos meses después Mariano Ruiz-Funes escribía a Jiménez de Asúa sobre sus problemas de salud que, no obstante, no le alejaban de la lectura y escritura ${ }^{49}$. En esa última carta anunciaba Ruiz-Funes a su entrañable amigo y compañero, Jiménez de Asúa, que había conseguido el contrato de profesor a tiempo completo. Pero poco después moría en el exilio sin haber tenido la posibilidad de retornar a España, hecho que fue tema de preocupación entre ambos intelectuales penalistas, imposibilidad que se hizo más notoria desde que en 1950 la ONU retiró el veto al Régimen de Franco. Fue entonces cuando Asúa escribió a Ruiz-Funes una dura carta, pocos meses después de este giro de la ONU, donde se expresaba plenamente consciente de la imposibilidad del retorno: la represión franquista había sido verdaderamente una política de tierra quemada, y afectó tanto a nivel personal como a nivel material y económico. Asúa escribió:

"Me saquearon la casa, me privaron de la biblioteca y el mes pasado acaban de ejecutar la multa que me impusieron apropiándose de una participación en unas minas de Bilbao que eran de mis abuelos" $" 50$.

El propio Asúa ahondaba en su sentimiento de nostalgia de la patria dejada atrás en su prólogo al Tratado de Derecho Penal (1950):

"Los años pasan e insensiblemente ponemos el pie en la linde en que la vida nos pesa, cargada de tiempo. Esta época larga y llena de añoranzas de la patria lejana, nos ha traído a

\footnotetext{
42 Jiménez de Asúa, Luis, "La legítima defensa del Estado", Revista de la Facultad de Derecho de México, Tomo VIII, n 59, enero-marzo 1958, pág. 60.

43 Ibídem, pág. 60.

${ }_{44}$ Abolicionismo del que fue firme defensor Mariano Ruiz-Funes en su obra Progresión bistórica de la pena de muerte en España, Madrid, 1934, que analizo en Gracia Arce, Beatriz, Trayectoria política e intelectual de Mariano Ruiz-Funes: República y exilio, Edit.um, Murcia, 2014, págs. 96-102.

45 Sánchez Tejerina, I, Nuevos problemas de Derecho Penal, Anuario de Derecho Penal, 1948, pág 240.

${ }^{46}$ Ferré Olivé, Juan Carlos, El derecho penal de la posguerra, Valencia, Tirant lo Blanch, 2016.

${ }^{47}$ Tébar Rubio-Manzanares, Ignacio, Derecho Penal del enemigo en el primer franquismo. Alicante, Ediciones Universidad de Alicante, 2017, pág. 50.

48 AHPI-ALJA, 421-43. Carta de Jiménez de Asúa a Ruiz-Funes, Buenos Aires, 30 de diciembre de 1952.

49 AHPI-ALJA, 421-43. Carta de Ruiz-Funes a Jiménez de Asúa, México, 6 de mayo de 1953.

50 AHPI-ALJA, 421-43. Carta de Jiménez de Asúa a Ruiz-Funes, Buenos Aires, 3 de febrero de 1951.
} 
los españoles republicanos muchas amarguras. La esperanza de retorno ha ido alejándose y casi se ha esfumado ahora" ${ }^{, 51}$.

La misma suerte había corrido Mariano Ruiz-Funes, quien fue inculpado por el Juzgado Especial de Responsabilidades Políticas de Albacete de los siguientes delitos:

“(...) Ser jefe del Partido Republicano de la Provincia de Murcia, ser diputado en las cortes constituyentes "donde hizo patente su irreligiosidad atacando a la Compañía de Jesús", propaganda disolvente, después del "glorioso Movimiento del 18 de julio fue Ministro del Gobierno Rojo y a la caída del conglomerado marxista fue nombrado Embajador en Polonia y luego en Bélgica; fue propagandista en toda la provincia en contra de la Monarquía, dando mítines; en los actos políticos siempre se caracterizaba por ir contra la iglesia católica; hizo mucha propaganda a favor de las izquierdas, teniéndose como uno de los responsables de los ocurrido durante la dominación roja" ${ }^{\prime 2}$.

La sanción impuesta a Mariano Ruiz-Funes en 1940, ya en el exilio, fue la inhabilitación absoluta y extrañamiento de 15 años, además de la incautación de todos sus bienes: en su caso, sus fincas y su biblioteca ${ }^{53}$.

Como criticaba el poema de León Felipe:

"Franco... tuya es la hacienda...

la casa, el caballo y la pistola...

Mía es la voz antigua de la tierra.

Tú te quedas con todo

y me dejas desnudo y errante por el mundo...

mas yo te dejo mudo... jmudo!...." 54 .

$\mathrm{Y}$ es que pese al exilio estos dos penalistas desarrollaron una fructífera carrera en el ámbito jurídico que se alejaba completamente de los postulados del sistema jurídico del Régimen franquista, basado en la venganza y en la depuración que, con carácter retroactivo, castigaba a todas aquellas personas que se habían significado por la República. Lejos de esta corriente, ellos, y muy en concreto Ruiz-Funes, apostaron por analizar y conceptualizar un nuevo derecho internacional que abogaba por los Derechos Humanos, la condena de los 'crímenes de guerra' y del genocidio ${ }^{55}$.

\section{Conclusiones: La huella difícilmente cuantificable del exilio.}

Las travesías e historias de vida en el exilio, tanto de Ruiz-Funes en México como de Jiménez de Asúa en Argentina, remiten al ejercicio de voces críticas que se manifiestan tanto a nivel político como en el ámbito jurídico y en su condición de profesores universitarios. Hicieron de su obra, en la larga travesía del destierro, un verdadero compromiso de resistencia ética contra la dictadura franquista. Pero la difícil tarea, llegados a este punto, es intentar dilucidar la huella que, a veces, se muestra difícilmente cuantificable del exilio español en América Latina.

\footnotetext{
51 Jiménez de Asúa, Luis, Tratado de Derecho Penal. Vol. I, Buenos Aires, Losada, 1950, pág. 14.

52 AUUM-FMRF, Caja 19 bis. Copia del expediente del Juzgado Especial de Responsabilidades Políticas que se encuentra en el CDMH de Salamanca, signaturas: 75/00183, 75/01218,75/01090. También en el Archivo General de la Región de Murcia: JUSTICIA, 11706. Expedientes de responsabilidades políticas. Años 1940-1943.

53 AUUM-FMRF, Caja 19 bis. Documento de la Delegación de Hacienda, donde se refleja que la biblioteca de Mariano Ruiz-Funes se componía de 900 volúmenes, y cerca de 600 folletos que fueron destinados a la Casa de la Cultura de Murcia, 13 de mayo de 1955.

${ }^{54}$ Felipe, León, Nueva antología rota, Madrid, Akal, 2008, pág. 177.

55 Véase Gracia Arce, Beatriz, "Mariano Ruiz-Funes y su aportación al exilio jurídico en México", Cuadernos Iberoamericanos. Revista de Historia y Comunicación (CIHC), N¹- año 2015, págs. 30-45.
} 
Se reconoce por la historiografía mexicana y española que la aportación que hizo el exilio republicano al impulso de la UNAM fue muy importante y significativo en lo que corresponde a la Facultad de Derecho, que recibió un importante número de docentes de universidades españolas, abogados y filósofos del derecho que habían sido los transformadores de la Universidad española en los años treinta y ahora trasladaban su conocimiento a México. Fruto de ello fue el programa de doctorado puesto en marcha, entre otros, por Ruiz-Funes, que posibilitó que "gran parte de lo que es el mundo del derecho mexicano se deba a la tarea silenciosa de esos maestros ${ }^{56 "}$, investigadores españoles que trajeron consigo aires nuevos, nuevos debates en un momento en el que las instituciones de educación superior mexicanas se encontraban en un largo proceso de reconstrucción después de la revolución y la experiencia transformadora de Cárdenas ${ }^{57}$. La enseñanza fue la función más importante de estos juristas exiliados, al tiempo que su trabajo contribuyó a estimular a sus colegas mexicanos ${ }^{58}$. A esto se suma el acicate que supusieron los exiliados, que introdujeron en la Escuela de Derecho la idea de una vida académica más sujeta a cánones y más disciplinada desde el punto de vista intelectual. En el caso de Ruiz-Funes, su labor no se circunscribió exclusivamente a esta labor docente, sino que se convirtió en un solicitado conferenciante en toda Latinoamérica, y fue precisamente con motivo de esta faceta suya de impartir conferencias allí donde se le llamase, que su hija Carmen le caracterizaba, si bien de forma entrañable y jovial, como de un "agente viajero del Derecho Penal ${ }^{59} \%$.

Esta importante labor que complementaba a la realizada en la enseñanza formal, revela la realidad de gran parte del profesorado exiliado que llegó a México: el enorme trabajo que tuvieron que realizar para subsistir en el destierro, lejos de la idílica realidad prefigurada por la inicial acogida del gobierno mexicano. La huella que dejaron los maestros del derecho en la Facultad de Derecho de la UNAM es reconocida por sus discípulos de forma constante. De hecho las publicaciones de la UNAM dedicaron en 2008 un ejemplar a homenajear al penalista murciano editado por Fernando Serrano Migallón y Raúl Carrancá y Rivas ${ }^{60}$, quienes valoran en Ruiz-Funes no sólo su talento en las artes jurídicas y su labor realizada en la UNAM, sino también su sensibilidad literaria. La revalorización de su obra también podemos observarla en la reedición por la prestigiosa editorial mexicana fundada por los exiliados españoles, Fondo de Cultura Económica de una de sus obras más interesantes elaboradas en el exilio mexicano, como fue Evolución del delito político $(1944)^{61}$. Las muestras de gratitud también quedaron recogidas tras los muros de la Facultad de Derecho de esta institución mexicana, a partir de la donación por parte

\footnotetext{
56 Serrano Migallón, Fernando, Los maestros del exilio español en la Facultad de Derecho, México, Porrúa, 2003, pág. X.

57 Serrano Migallón, Fernando, La inteligencia peregrina. Legado de los intelectuales del exilio republicano en México, México, Colegio de México-Fondo de Cultura Económica, 2010, pág. 134-135.

${ }^{58}$ Marcó del Pont, Luis, Criminólogos españoles del exilio, Centro de publicaciones de la Secretaria General Técnica, Ministerio de Justicia, Madrid, 1986. Reyes Nevares, Sa, "Juristas, economistas, sociólogos", en VV.AA, El exilio español en México, 1939-1982, Salvat y Fondo de Cultura Económica, México, 1982, págs. 567-598. Arenal, Julio del, Un modo de ser libres. Independencia y constitucionalismo en México, Zamora, Colmich, 2002, quien ha destacado el impulso de Ruiz-Funes y de otros especialistas del exilio español en la dinamización, expansión y profundización del estudio y del ejercicio del Derecho en México.

${ }^{59}$ Ruiz-Funes, Concepción, “Mariano Ruiz-Funes. Penalista en el exilio”, en Egido León, Ángeles, Republicanos en la memoria. Az̧ã̃a y los suyos, Madrid, Eneida, 2006, pág. 169.

60 VVAA., Homenaje al Doctor Mariano Ruiz-Funes. El derecho y sus maestros, $\mathrm{n}^{\circ}$ 34, 2008. También hay que resaltar el discurso que pronunció Raúl Carranca el 10 de octubre de 2003 con motivo de la imposición de la placa conmemorativa en la Facultad de Derecho de la UNAM dedicada a los profesores de la emigración española, en http://www.doctorraulcarrancayrivas.com/refugiados.htm (última consulta el 30/04/2017). En octubre de 2010, Néstor de Buen también tendría un recuerdo afectuoso en un artículo publicado en La Jornada de México para con los profesores del exilio en el 100 aniversario de la UNAM. Puede consultarse en
} http://www.jornada.unam.mx/2010/10/03/opinion/021a1pol (última consulta el 30/04/2017).

${ }^{61}$ Ruiz-Funes, Mariano, Evolución del delito politico, México, Fondo de Cultura Económica, 2013. 
de la familia Ruiz-Funes de la biblioteca que el penalista consiguió reunir en el exilio, y que dotan de continuidad a la faceta que, posiblemente, más disfrutó Ruiz-Funes, la de profesor.

Por su parte, Luis Jiménez de Asúa se convirtió en su exilio argentino en uno de los penalistas más importantes y maestro de otros muchos. Su huella se puede observar incluso en aquellos que, como él, tuvieron que marchar al exilio, tal es el caso de Francisco de Ayala, quien fue su discípulo y trabajó con él en la embajada de Praga, como señala en sus memorias ${ }^{62}$. El reconocimiento por parte del gremio en Latinoamérica es unánime, y su Tratado de Derecho Penal (1950-1970) fue una obra de indiscutible consulta para los estudiantes argentinos, así como sus estudios que profundizaban en el derecho penal comparado. A su muerte en Buenos Aires, en 1970, distintos países le brindaron homenaje, como Chile; el Senado de Venezuela y, por supuesto, la Universidad de La Plata.

La ingente obra de los dos penalistas exiliados, Ruiz-Funes y Jiménez de Asúa, invita a seguir reflexionando sobre ella y a mostrar la trascendencia que ambos intelectuales tuvieron en sus respectivos exilios, en México y Argentina. En definitiva, a seguir sus huellas y travesías, pues se vislumbra muy necesario comprobar el influjo humanista y democrático de éstos y de otros juristas en Latinoamérica, sobre todo en lo que respecta a una concepción de la Justicia y la Víctima tan lejos y opuesta a las formas y fórmulas jurídicas que por esos mismos años se estaban desarrollando en la España de la dictadura franquista y su Universidad, vigilada, dirigida y permeada por la imperante e intransigente ideología nacional-católica.

\footnotetext{
${ }^{62}$ Ayala, Francisco, Recuerdos y olvidos, Madrid, Alianza, 1982, pág. 221.
} 